\title{
Matrix Metalloproteinase-9 and Haemozoin: Wedding Rings for Human Host and Plasmodium falciparum Parasite in Complicated Malaria
}

\author{
Mauro Prato and Giuliana Giribaldi \\ Dipartimento di Genetica, Biologia e Biochimica, Facoltà di Medicina e Chirurgia, Università di Torino, Via Santena 5 bis, \\ 10126 Torino, Italy \\ Correspondence should be addressed to Mauro Prato, mauro.prato@unito.it
}

Received 31 December 2010; Accepted 7 March 2011

Academic Editor: Sasithon Pukrittayakamee

Copyright ( $) 2011$ M. Prato and G. Giribaldi. This is an open access article distributed under the Creative Commons Attribution License, which permits unrestricted use, distribution, and reproduction in any medium, provided the original work is properly cited.

It is generally accepted that the combination of both Plasmodium falciparum parasite and human host factors is involved in the pathogenesis of complicated severe malaria, including cerebral malaria (CM). Among parasite products, the malarial pigment haemozoin (HZ) has been shown to impair the functions of mononuclear and endothelial cells. Different CM models were associated with enhanced levels of matrix metalloproteinases (MMPs), a family of proteolytic enzymes able to disrupt subendothelial basement membrane and tight junctions and shed, activate, or inactivate cytokines, chemokines, and other MMPs through cleavage from their precursors. Among MMPs, a good candidate for targeted therapy might be MMP-9, whose mRNA and protein expression enhancement as well as direct proenzyme activation by HZ have been recently investigated in a series of studies by our group and others. In the present paper the role of HZ and MMP-9 in complicated malaria, as well as their interactions, will be discussed.

\section{Introduction}

Among protozoan parasites of the genus Plasmodium, P. falciparum is the most deadly agent of human malaria, causing a broad spectrum of clinical manifestations ranging from asymptomatic to severe multiorgan disease. Despite recent major efforts by the research community, malaria remains one of the major diseases in poor areas, including SubSaharan Africa and South-East Asia. It is associated with several million clinical cases per year and leads annually to over one million deaths $[1,2]$. The pathophysiology of severe malaria complications is not well understood. In some cases, including cerebral malaria (CM), renal failure, lung pathology and malaria during pregnancy, it appears associated with cytoadherence and sequestration of $P$. falciparum-parasitized red blood cells (pRBCs) to vascular endothelium, leading to microcirculatory obstruction, tissue hypoxia, and metabolic disturbances [3-5]. In some cases additional leukocyte extravasation has been reported $[6,7]$.
As described in the following sections, either pRBCs or parasite products such as haemozoin (HZ, malarial pigment), a lipid-enriched ferriprotoporphyrin IX crystal derived from haemoglobin catabolism by the parasite [8], can modulate the functions of mononuclear and endothelial cells and promote the production of proinflammatory molecules and other soluble factors, including matrix metalloproteinases (MMPs). MMPs are a well-known family of proteolytic enzymes able to disrupt subendothelial basement membranes $[9,10]$, to destroy tight junctions [11], and to shed, activate, or inactivate cytokines, chemokines, and other MMPs through cleavage from their precursors [12-14]. In the last decade, growing evidence on involvement of MMPs in falciparum malaria became available: human postmortem studies showed enhanced protein levels of MMP-1 in brains of CM patients [15], whereas MMP-8 was found increased in plasma of severe malaria patients [16]; additionally, activation of the human MMP-9 gene by $P$. falciparum has been reported in microarray studies on whole blood from 


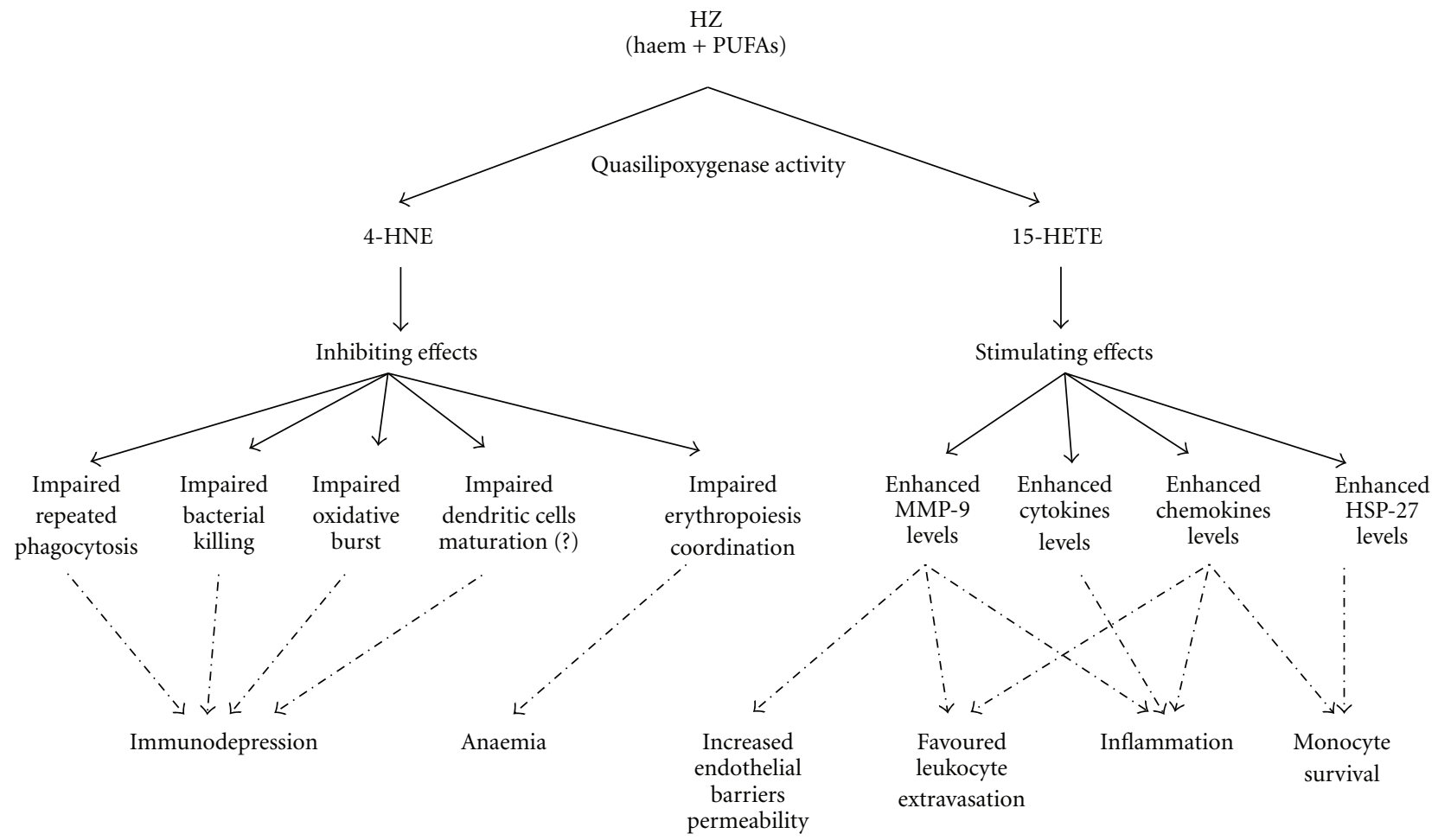

FIgURE 1: Effects of phagocytosis of $\mathrm{HZ}$ on human monocyte functions.

children with malaria [17]. Interestingly, a role for MMPs during malaria is suggested also by evidence from nonhuman models of CM: in the brain of mice infected by P. Berghei ANKA, the etiological agent of murine CM, increased MMP2, MMP-7, and MMP-9 levels, and pro-MMP-9 activation were found $[18,19]$.

The present paper will explore the effects of $\mathrm{HZ}$ on functions of mononuclear and endothelial cells, focusing on regulation of human MMP-9, which at present among the malaria-related MMPs is the most studied and could be a potential target for adjunctive therapy of complicated severe malaria.

\section{Effects of HZ on Human Mononuclear and Endothelial Cells}

$\mathrm{HZ}$ is a birefringent crystalline material made of $\mathrm{Fe}^{3+}$ Protoporphyrin IX dimers that derives from the degradation of haemoglobin by intraerythrocytic Plasmodium [8]. Unpurified HZ contains also unspecifically attached polyunsaturated fatty acids (PUFAs) such as arachidonic and linolenic acids, originating from membranes of Plasmodium digestive vacuoles [20]. The presence in unpurified $\mathrm{HZ}$ of large quantities of ferric haem with small amounts of free iron makes $\mathrm{HZ}$ a generator of oxidative radicals capable of forming lipoperoxides or other breakdown products from PUFAs (quasilipoxygenase activity) [21]. Analysis of the lipid fraction isolated from native $\mathrm{HZ}$ showed large amounts of hydroxyeicosatetraenoic acids (HETEs), hydroxyoctadeca- dienoic acids (HODEs), and the terminal aldehyde 4-hydroxynonenal (4-HNE) [22].

$\mathrm{HZ}$ is avidly phagocytosed by human monocytes, and the fatal risk for patients with severe falciparum malaria has been reported to be directly proportional to levels of HZcontaining monocytes in peripheral blood [25]. After phagocytosis of $\mathrm{HZ}$, several monocyte functions are dramatically impaired, as shown in Figure 1. The effects of $\mathrm{HZ}$ on human monocytes are either inhibiting or stimulating. A detrimental case of functional inhibition led by $\mathrm{HZ}$ phagocytosis is represented by immunodepression. As evidenced from in vitro studies, HZ-fed human monocytes showed impairment of repeated phagocytosis [26], bacterial killing abilities [27], and oxidative burst [28]. Additionally HZ-laden monocytes did not respond to IFN-gamma stimulation and failed in MHC Class II expression, with following disturbances in antigen presentation [29]. These effects appear to be dependent on the lipid moiety of HZ, and low doses of 4$\mathrm{HNE}$ have been reported to mimic $\mathrm{HZ}$ action by inhibiting the IFN-gamma-mediated MHC Class II expression [30]. On the contrary, the inhibitory role of HZ on monocyte differentiation/maturation to dendritic cells is less clear, since similar in vitro studies by different authors led to opposite results, showing either inhibition [31] or enhancement $[32,33]$ of differentiation/maturation to dendritic cells. HZ appears also to be related indirectly to anaemia, as HZfed monocytes are not able to coordinate the maturation of erythroid precursors; also in this case a role for 4HNE in HZ-dependent inhibition of erythropoiesis has been proposed [34]. Regarding the stimulating effects of malarial 
pigment, HZ-laden monocytes have been shown to overproduce a large series of proinflammatory molecules, including cytokines (TNF, IL-1 beta, and IL-1RA), chemokines (IL8/CXCL8, ENA-78/CXCL5, GRO $\alpha$, GRO $\beta$, GRO $\gamma$, MIP$1 \alpha$, MIP- $1 \beta$, and MCP-1) and the cyto/chemokine-related proteolytic enzyme MMP-9 [23, 35-38]. The lipid moiety of $\mathrm{HZ}$ appears to be responsible for these effects, and a major role for 15-HETE has been proposed. Due to the important direct connections to MMP-9, the mechanisms underlying the HZ-triggered pro-inflammatory response will be deeply discussed in a following dedicated section. Curiously, although HZ compromises a large number of monocyte functions, leading to rapid inflammatory response, it has been recently shown that HZ-laden monocytes do not undergo apoptosis. To explain such an apparent dichotomy, a role for heat shock protein-27 (HSP-27), a chemokinedependent molecule with antiapoptotic properties, has been recently proposed by our group. Indeed, in two models in vitro we showed HZ-dependent upregulation of HSP-27 either in immunopurified monocytes from peripheral blood or in the THP-1 monocytic cell line $[38,39]$.

Anyway, phagocytic cells such as monocytes are not the only human cells which appear to be influenced by HZ. Few data are also available on direct alterations of the human endothelial cell phenotype by HZ. Such a change might be dramatically detrimental during $\mathrm{CM}$, since endothelial cells are a crucial component of the blood-brain barrier (BBB). At present, $\mathrm{HZ}$ has been reported to enhance either basal or cytokine-induced levels of adhesion molecules $[40,41]$ and to inhibit the release of the vasoconstrictor mediator ET-1 [42-44]. Additionally, recent evidence from human microvascular endothelial cells (HMECs) as well as human umbilical vein endothelial cells (HUVECs) showed enhancement or de novo induction of protein expression and activity of several MMPs, including MMP-1, MMP-3, and MMP-9. This topic will be deepened in the following sections.

\section{Involvement of MMP-9 in Complicated Severe Malaria}

MMP-9 is produced by several cells, including mononuclear and endothelial cells.

Structurally, MMP-9 shares with the other members of the MMP family the following conserved domains: a prodomain, an active domain, a $\mathrm{Zn}^{2+}$-binding domain and a carboxyterminal haemopexin domain (which is absent in MMP7 and MMP-26). In addition MMP-9, as well as the other gelatinase MMP-2, has a gelatin-binding fibronectin domain, composed of three fibronectin repeats, inserted between the active-site domain and the $\mathrm{Zn}^{2+}$-binding domain, plus an additional collagen type $\mathrm{V}$ domain in a particular hinge region. The $\mathrm{Zn}^{2+}$-binding domain, which contains three histidines responsible for the coordination of the catalytic $\mathrm{Zn}^{2+}$ ion, forms the active site with the active domain and is required for the enzymatic activity. The fourth ligand of the $\mathrm{Zn}^{2+}$ ion is a cysteine of the prodomain. This propeptide can be removed by proteolysis or distorted by substrate binding.
The haemopexin domain plays a role in the substrate specificity and is important for the binding of the tissue inhibitors of metalloproteinases (TIMPs). The fibronectin repeats are related to gelatin, laminin, and collagens I/IV binding $[9,10,45]$.

In the last decade, few evidence of direct involvement of MMP-9 in severe malaria has been reported. Activation of the human MMP-9 gene by P. falciparum has been shown in microarray studies on whole blood from children with severe malaria [17], whereas MMP-9 increases in cerebrospinal fluid levels were not apparent, possibly because of the enzyme's tight association with the extracellular matrix [46]. At present no studies of MMP-9 in human postmortem brain tissues have been reported, but MMP-9 levels have been shown to be strongly upregulated in C57BL/6 mice brain infected with $P$. berghei ANKA, a murine model of CM sharing similar characteristics with human CM. Elevated MMP-9 levels were selective for the central nervous system, where they were found associated with the vasculature and parenchyma whereas immunohistochemistry showed that higher amounts of MMP-9 were produced by cells of monocytic lineage $(\mathrm{CD} 11 \mathrm{~b}+)$ [18].

Activation of pro-MMP-9 by removal of the propeptide may occur through several proteolytic mechanisms. It is well known that it can be processed and further activated through a proteolytic cascade involving plasminogen, MMP3 and MMP-1 [13, 47-49]. Interestingly, an accumulation of urokinase-type plasminogen activator receptor (uPAR) and MMP-1 has been described in brain of patients who died with CM $[15,50]$. Furthermore, increased levels of MMP3 in brain and spleen were observed in the murine model of CM previously cited [18]. Alternative mechanisms for proMMP-9 activation involve MMP-2 [51] and MMP-7 [52]. These molecules have not been studied yet in human malaria. However, in CM murine models, MMP-2 mRNA and protein were upregulated in brain [18] and MMP-7 mRNA was increased in liver but not in brain [18], whereas MMP-7 protein was increased in brain [19].

After secretion and activation, MMP-9 activity can still be regulated by degradation or inhibition. MMP-9 is inhibited not specifically by alpha2-macroglobulin and specifically by TIMPs, TIMP-1 showing the highest affinity for MMP-9 [53]. Inhibition of the activated MMP-9 occurs through interaction between the N-terminal domains of TIMP- 1 and the active site of the enzyme [54]. The C-terminal part of MMP-9 is also involved, and seems to be responsible for high-affinity interaction with TIMP-1 [55]. Recently, Dietmann et al. measured serum levels of several TIMPs and MMPs in patients with severe malaria [16] and found that elevated TIMP-1 was associated with signs and symptoms of severe malaria; in the same study the authors detected increased levels of MMP-8, but not of MMP-9. MMP-9 is also inhibited by a large number of synthetic compounds [5658]. Interestingly, antimalarial artemisinin- and artemisininderived drugs also showed anti-MMP-9 properties [59-62].

Functionally, MMP-9 is able to process a large pattern of molecules, including matrix proteins, inflammatory factors, surface molecules, and intercellular junctions [12, 14]. Among these substrates, several have been associated to 
TABLE 1: Substrates of MMP-9 that might be critical to complicated severe malaria.

\begin{tabular}{|c|c|c|c|}
\hline MMP-9 substrate & Functional classification & Effect of MMP-9 proteolytic activity & References \\
\hline Pro-TNF & Cytokine proform & Shedding & {$[63]$} \\
\hline Pro IL-1beta & Cytokine proform & Activation & {$[64]$} \\
\hline IL-1beta & Cytokine & Degradation & {$[65]$} \\
\hline Pro-TGF-beta & Cytokine proform & Activation & {$[66]$} \\
\hline GRO-alpha/CXCL1 & Chemokine & Degradation & {$[67]$} \\
\hline PF-4/CXCL4 & Chemokine & Degradation & {$[67]$} \\
\hline ENA-78/CXCL5 & Chemokine & Transient potentiation, further inhibition & {$[68]$} \\
\hline GCP-2/CXCL6 & Chemokine & No effects & {$[68]$} \\
\hline NAP-2/CXCL7 & Chemokine & Degradation & {$[67]$} \\
\hline IL-8/CXCL8 & Chemokine & Potentiation & {$[67]$} \\
\hline MIG/CXCL9 & Chemokine & Inhibition & {$[69]$} \\
\hline IP-10/CXCL10 & Chemokine & Degradation & {$[69]$} \\
\hline SDF-1/CXCL12 & Chemokine & Inhibition & {$[70]$} \\
\hline ICAM-1 & Cell surface protein & Inhibition & {$[71]$} \\
\hline IL-2R-alpha & Cell surface protein & Inhibition & {$[72]$} \\
\hline Occludin & Intercellular junction & Degradation & {$[73]$} \\
\hline $\mathrm{ZO}-1$ & Intercellular junction & Degradation & {$[74]$} \\
\hline $\mathrm{ZO}-2$ & Intercellular junction & Degradation (hypothesis) & {$[75]$} \\
\hline Claudin-1 & Intercellular junction & Degradation & {$[76]$} \\
\hline Claudin-2 & Intercellular junction & Degradation (hypothesis) & {$[77]$} \\
\hline Claudin-4 & Intercellular junction & Activation (hypothesis) & {$[78]$} \\
\hline Claudin-5 & Intercellular junction & Degradation (to be further investigated) & {$[79]$} \\
\hline Syndecan-1 & Structural protein & Shedding & {$[80]$} \\
\hline $\mathrm{MBP}$ & Structural protein & Degradation & {$[81]$} \\
\hline Beta-dystroglycan & Structural protein & Degradation & {$[82]$} \\
\hline
\end{tabular}

severe malaria. Table 1 lists the principal MMP-9 substrates which might be relevant for malaria studies. The indicated molecules are either soluble factors (cytokines, chemokines) or membrane-associated proteins (pro-TNF, cell surface proteins, and intercellular junctions). All these molecules appear to be crucial for the development of complications of severe malaria, and their overbalanced regulation is often associated to CM. This is characterized by cytoadherence and sequestering of pRBCs to brain endothelial cells through ICAM-1, followed by an elevated inflammatory response, with high production of TNF and IL-1 beta, as well as several chemokines, which might recruit mononuclear cells and favour monocyte extravasation through the blood-brain barrier (BBB), which appears leaky due to the disruption of tight junctions ZO-1, claudin-5, and occludin [6, 7, 8390]. Thus, in order to better understand and eventually prevent the mechanisms underlying $\mathrm{CM}$, in the future it will be certainly intriguing to investigate the effects of MMP-9 on these molecules in complicated severe malaria models. Interestingly, the gene induction as well as the direct activation of MMP-9 by HZ has been demonstrated in vitro either in mononuclear or on endothelial cells, and an active role for HZ-dependent enhancement of soluble TNF production by human monocytes has already been demonstrated [23], as it will be discussed in the following section.

\section{Interactions between HZ and MMP-9}

The relationship between falciparum HZ and human MMP9, as well as several related molecules, has been investigated in-depth in a series of recent works. In an elegant work Geurts et al. demonstrated that pro-MMP-9 binds directly to the beta-haematin core of HZ through its haemopexin domain, resulting in priming of the activation of the zymogen by other MMPs [91]. In human monocytes $\mathrm{HZ}$ has been reported to influence the MMP-9 gene and protein expression, as well as following protein release. Experiments by Real Time RT-PCR have shown that HZ and HZ-containing trophozoites enhanced the mRNA expression of MMP-9 [23]. HZ-dependent MMP-9 gene induction was also confirmed by additional microarray [92] and macroarray [38] studies. As a consequence, pro-MMP-9 protein expression was found to be increased [23]. The degranulation of gelatinase granules with MMP-9, lysozyme, and TIMP-1 was also promoted, as demonstrated by data showing HZ/trophozoite-dependent enhanced release of active MMP-9 [23], lysozyme [93, 94], and TIMP-1 [94] in monocyte cell supernatants. As a result, the total gelatinolytic activity of monocytes was increased by HZ [94] and cells were able to migrate through extracellular matrix [23].

The production of several soluble factors related to MMP-9 has also been studied. HZ and trophozoites were shown to stimulate the release of TNF [23] and IL-1 beta 

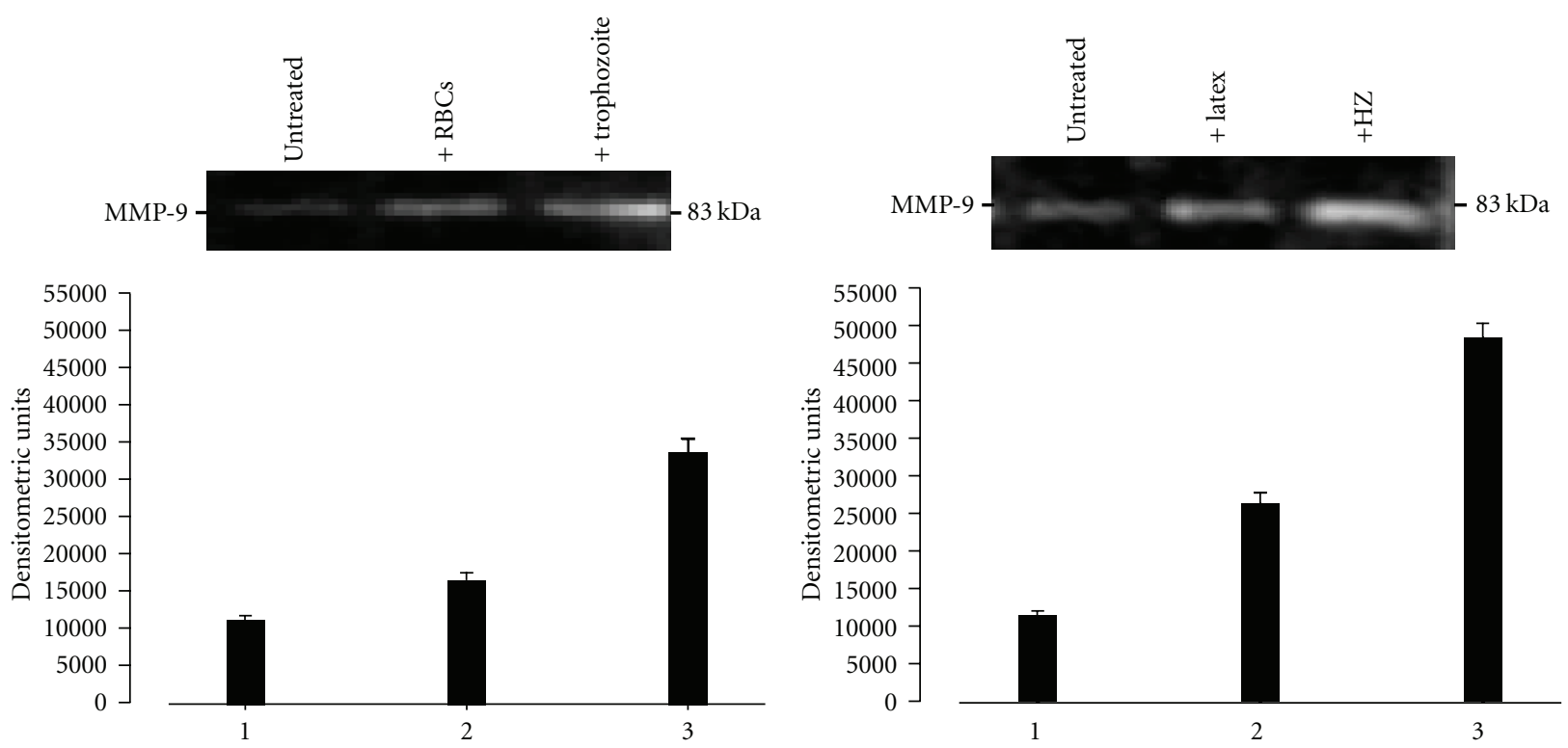

(a)

(b)

FIgURE 2: HZ-containing pRBCs (trophozoites) and free HZ enhance MMP-9 levels in HUVECs. Untreated cells (column/lane 1, both panels), cells treated with uninfected RBCs or latex as control stimuli (column/lane 2, (a) and (b) resp.), and cells treated with HZcontaining-trophozoites or HZ (column/lane 3, (a) and (b), resp.) were incubated for $48 \mathrm{~h}$. At the end of the treatment, MMP-9 levels were measured in HUVEC supernatants by SDS-PAGE gelatin zymography and densitometric analysis through a computerized densitometer as previously described $[23,24]$. Column data (lower panels) are mean values of arbitrary densitometric units + SEM of three independent experiments; gel data (upper panels) are from one representative experiment; the 83-kDa negative bands in the gel indicate MMP-9 levels. Data were analyzed for significance by Student's $t$-test and all differences were significant ((a) 1 versus $2: P<.02 ; 1$ versus $3: P<.001 ; 2$ versus 3: $P<.002$. (b) 1 versus $2: P<.001 ; 1$ versus 3 : $P<.0001 ; 2$ versus $3: P<.001$ ).

[37] by human monocytes. These cytokines, which can modulate the MMP-9 gene expression $[95,96]$, have been shown to play a crucial role in HZ-dependent enhancement, since the use of anti-TNF and anti-IL-1beta antibodies abrogated the previous HZ effects on pro-MMP-9 expression and active MMP-9 release [23,37]. Anti-TNF antibodies also blocked the HZ-dependent release of active lysozyme [93]. Interestingly, pro-TNF and pro-IL-1 beta are also two molecular substrates of MMP-9 (see Table 1); as a consequence of cleavage by MMP-9, the soluble TNF is shed from its membrane-bound precursor [63], whereas IL-1 beta is directly activated after removal of the propeptide [64]. The use of a synthetic inhibitor of MMP-9 was shown to abrogate the HZ-dependent enhancement of TNF release by human monocytes [23]. Such an evidence demonstrated that during malaria a pathological autoenhancing loop between MMP-9 and TNF is likely, and the inhibition of MMP-9 could be particularly important in order to avoid detrimental inflammatory effects during complicated malaria, CM above all. On the other hand, the MMP-9 inhibitor did not alter the HZ-enhanced release of IL-1 beta [37], suggesting that in HZ-fed monocytes the production of IL-1 beta precedes the MMP-9 enhancement. This hypothesis was confirmed by recent time-dependent macroarray studies on expression of inflammatory genes, showing that praecox IL-1 beta mRNA expression was already present $2 \mathrm{~h}$ after exposure of human monocytes to HZ; therefore, IL-1beta was rapidly endorsed by additional transcription of other inflammatory genes, including MMP-9, TNF, IL-1RA, and several chemokines (IL-8/CXCL8, ENA-78/CXCL5, GROalpha/CXCL1, GRObeta, GRO-gamma, MIP-1 alpha, MIP-1 beta, and MCP-1) [38]. Moreover, crossed experiments with anti-TNF and anti-IL-1beta blocking antibodies suggested that the production of IL-1 beta was earlier than TNF production [37].

Recently, the effects of HZ on MMP-9 regulation have been also studied in endothelial cells. MMP-9 protein expression and release was shown to be dose-dependently induced de novo by HZ in HMECs and to enhance total gelatinolytic activity; as a consequence, cells displayed morphological changes, showing elongated shape and increased ability to form microtubule-like structures through extracellular matrix. In the same work, the enhanced expression of MMP-1 and MMP-3, two enzymes causally connected in the cascade of activation of pro-MMP-9, was also described [97]. Additional data for endothelial cells from large calibre vessels are described in Figure 2, showing that HZ and HZ-containing trophozoites were able to enhance basal levels of activated MMP-9 released in cell supernatants from HUVEC cultures.

Further studies performed either on mononuclear or endothelial cells were aimed to clarify what component (haem or lipid moiety) was responsible for the effects of $\mathrm{HZ}$ on MMP-9 and related soluble factors described above. In human monocytes the use of delipidized native or lipid-free synthetic HZ did not reproduce the enhancing effects of $\mathrm{HZ}$ on MMP-9 levels [37], gelatinolytic activity [94], lysozyme 


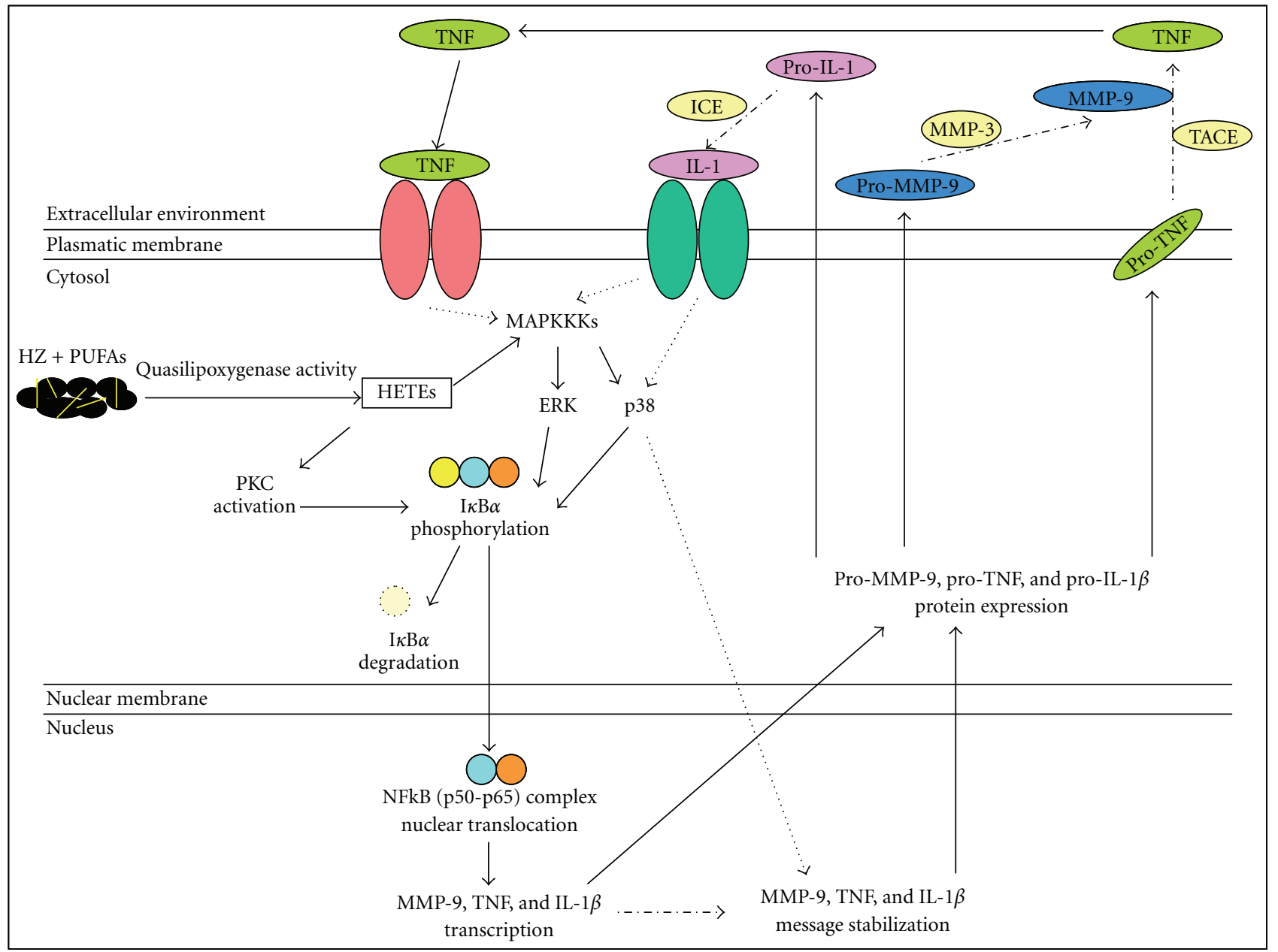

FIgURE 3: Putative mechanisms through which HZ and 15-HETE might promote NF-kappaB-controlled gene expression of MMP-9 and related molecules.

release [94], and production of TNF [98], IL-1 beta [37], and several chemokines [38], suggesting a major role for the lipid moiety of HZ. Further investigation suggested that a valid candidate responsible for HZ stimulatory effects could be 15HETE, since micromolar doses of this compound mimicked $\mathrm{HZ}$ effects on all previous parameters [37, 38, 94, 98]. A role for the lipid moiety of $\mathrm{HZ}$ has been also proposed to explain the HZ effects on HMECs, since delipidized and synthetic HZ did not affect MMP-9, MMP-3, and MMP-1 protein expression [97].

Finally, a mechanism involving NF-kappaB activation has been recently proposed to explain how HZ and 15HETE might promote the production of MMP-9 and related molecules in human monocytes. After phagocytosis of HZ and trophozoites, as well as stimulation with 15-HETE, the phosphorylation and degradation of cytosolic IkappaB-alpha protein and the following nuclear translocation of the NFkappaB complex were promoted either in short-term $(2 \mathrm{~h}$ after phagocytosis) or long-term ( $24 \mathrm{~h}$ after phagocytosis) studies. These events appeared directly related to HZdependent enhancement of MMP-9 release and production of TNF and IL-1 beta, since the use of NF-kappaB inhibitors showing antimalarial properties (quercetin, artemisinin, and parthenolide) abrogated the effects of both HZ and 15-HETE [61]. Additionally, the same inhibitors also abrogated the 15HETE enhancing effects on total gelatinolytic and lysozyme activity [94]. In another study using a monocytic cell line (THP-1), an extract from a plant with antimalarial properties (Punica granatum) inhibited HZ-dependent enhancement of MMP-9 expression and secretion by blocking the NFkappaB-driven transcription [99]. The previous literature data have shown that HETEs are peroxisome proliferatoractivated receptor-gamma ligands inhibiting the production of inflammatory cytokines and suppressing the NF-kappaB system. However, alternative mechanisms which might lead to HETEs-driven NF-kappaB activation have also been documented. A first alternative activation of NF-kappaB is based on HETE-mediated activation of protein kinase C [100-102] which in turn activates IKK [103], the kinase responsible for IkappaB-alpha phosphorylation and degradation [104], and subsequent nuclear translocation of NF-kappaB. Transient activation of protein kinase C by $\mathrm{HZ}$ [105] may thus explain the first NF-kappaB activation peak revealed $2 \mathrm{~h}$ after $\mathrm{HZ}$ phagocytosis. A second alternative activation of 
NF-kappaB [106] was found to involve MAP kinases, ERK, and $\mathrm{p} 38$ cascade. The p38 cascade was also proposed for HETEs-dependent modulation of TNF [107] and MMP-9 [108]. Interestingly, ERK-1/2 phosphorylation by HZ has been documented in a murine system [109]. A third alternative activation of NF-kappaB may result from the direct oxidation and inactivation of IkappaB by lipid hydroperoxides [110]. Figure 3 summarizes the putative mechanisms through which $\mathrm{HZ}$ and HETEs might activate the NF-kappaB transcription system and promote the following enhancement of gene induction of MMP-9 and related cytokines.

\section{Conclusions}

Evidence of the involvement of MMPs in complicated severe malaria has been emerging during the last decade, and HZ-dependent induction of MMP-9 expression and activity has been demonstrated in mononuclear or endothelial cells. Since several MMP inhibitors are already available as potential therapeutic tools in other pathologies [55-57], MMPs should be taken in account as potential new targets for an innovative and adjunctive therapy for severe malaria.

\section{Abbreviations}

HZ: Haemozoin

MMP: Matrix metalloproteinase

CM: Cerebral malaria

HMEC: Human microvascular endothelial cell

HUVEC: Human umbilical vein endothelial cell

BBB: $\quad$ Blood-brain barrier

MHC: Major histocompatibility complex

PUFA: Polyunsaturated fatty acid

HETE: Hydroxyeicosatetraenoic acid

HODE: Hydroxyoctadecadienoic acid

HNE: Hydroxynonenal

TIMP: Tissue inhibitor of metalloproteinase

TNF: $\quad$ Tumor necrosis factor

IL: Interleukin

ICAM: Intercellular adhesion molecule

uPAR: Urokinase-type plasminogen activator receptor

TGF: $\quad$ Transforming growth factor

ZO: Zonula occludens

MBP: $\quad$ Mannose binding protein

GRO: Growth-regulated oncogene

PF: $\quad$ Platele factor

ENA: Epithelial neutrophil activating peptide

MIP: $\quad$ Macrophage inflammatory protein

MCP: Monocyte chemoattractant protein

GCP: Granulocyte chemotactic protein

NAP: Neutrophil attractant-activation protein

MIG: Monokine induced by interferon-gamma

IP: Interferon-gamma-inducible protein

SDF: $\quad$ Stromal derived factor

ET: $\quad$ Endothelin

HSP: Heat shock protein.

\section{Acknowledgments}

Thanks are due to Dr. Simona Cardaropoli for her help with HUVEC cultures and to Dr. Nicoletta Basilico, Professor Donatella Taramelli, Dr. Philippe Van den Steen and Professor Ghislain Opdenakker for their precious suggestions and stimulating discussions. This study was supported by University of Torino Intramural Funds to GG, by grants from Compagnia di San Paolo to MP in the context of the Italian Malaria Network and by kind supplemental donation from Mrs. Franca Squazza to MP. The authors have no conflicting financial interests.

\section{References}

[1] S. C. Murphy and J. G. Breman, "GAPS in the childhood malaria burden in Africa: cerebral malaria, neurological sequelae, anemia, respiratory distress, hypoglycemia, and complications of pregnancy," American Journal of Tropical Medicine and Hygiene, vol. 64, no. 1-2, pp. 57-67, 2001.

[2] A. Khadjavi, G. Giribaldi, and M. Prato, "From control to eradication of malaria: the end of being stuck in second gear?" Asian Pacific Journal of Tropical Medicine, vol. 3, no. 5, pp. 412-420, 2010.

[3] H. Brown, S. Rogerson, T. Taylor et al., "Blood-brain barrier function in cerebral malaria in Malawian children," American Journal of Tropical Medicine and Hygiene, vol. 64, no. 3-4, pp. 207-213, 2001.

[4] K. T. Andrews and M. Lanzer, "Maternal malaria: Plasmodium falciparum sequestration in the placenta," Parasitology Research, vol. 88, no. 8, pp. 715-723, 2002.

[5] J. G. Beeson, J. C. Reeder, S. J. Rogerson, and G. V. Brown, "Parasite adhesion and immune evasion in placental malaria," Trends in Parasitology, vol. 17, no. 7, pp. 331-337, 2001.

[6] J. K. Patnaik, B. S. Das, S. K. Mishra, S. Mohanty, S. K. Satpathy, and D. Mohanty, "Vascular clogging, mononuclear cell margination, and enhanced vascular permeability in the pathogenesis of human cerebral malaria," American Journal of Tropical Medicine and Hygiene, vol. 51, no. 5, pp. 642-647, 1994.

[7] G. E. Grau, C. D. Mackenzie, R. A. Carr et al., "Platelet accumulation in brain microvessels in fatal pediatric cerebral malaria," Journal of Infectious Diseases, vol. 187, no. 3, pp. 461-466, 2003.

[8] A. F. G. Slater, W. J. Swiggard, B. R. Orton et al., "An ironcarboxylate bond links the heme units of malaria pigment," Proceedings of the National Academy of Sciences of the United States of America, vol. 88, no. 2, pp. 325-329, 1991.

[9] H. Nagaset and J. F. Woessner, "Matrix metalloproteinases," Journal of Biological Chemistry, vol. 274, no. 31, pp. 2149121494, 1999.

[10] G. Opdenakker, P. E. Van den Steen, B. Dubois et al., "Gelatinase B functions as regulator and effector in leukocyte biology," Journal of Leukocyte Biology, vol. 69, no. 6, pp. 851859, 2001.

[11] G. A. Rosenberg and Y. Yang, "Vasogenic edema due to tight junction disruption by matrix metalloproteinases in cerebral ischemia," Neurosurgical focus, vol. 22, no. 5, p. E4, 2007.

[12] B. Cauwe, P. E. Van den Steen, and G. Opdenakker, "The biochemical, biological, and pathological kaleidoscope of cell surface substrates processed by matrix metalloproteinases," Critical Reviews in Biochemistry and Molecular Biology, vol. 42, no. 3, pp. 113-185, 2007. 
[13] M. L. Cuzner and G. Opdenakker, "Plasminogen activators and matrix metalloproteases, mediators of extracellular proteolysis in inflammatory demyelination of the central nervous system," Journal of Neuroimmunology, vol. 94, no. 12, pp. 1-14, 1999.

[14] P. Van Lint and C. Libert, "Chemokine and cytokine processing by matrix metalloproteinases and its effect on leukocyte migration and inflammation," Journal of Leukocyte Biology, vol. 82, no. 6, pp. 1375-1381, 2007.

[15] M. H. Deininger, S. Winkler, P. G. Kremsner, R. Meyermann, and H. J. Schluesener, "Angiogenic proteins in brains of patients who died with cerebral malaria," Journal of Neuroimmunology, vol. 142, no. 1-2, pp. 101-111, 2003.

[16] A. Dietmann, R. Helbok, P. Lackner et al., "Matrix metalloproteinases and their tissue inhibitors (TIMPs) in Plasmodium falciparum malaria: serum levels of TIMP-1 are associated with disease severity," Journal of Infectious Diseases, vol. 197, no. 11, pp. 1614-1620, 2008.

[17] M. J. Griffiths, M. J. Shafi, S. J. Popper et al., "Genomewide analysis of the host response to malaria in Kenyan children," Journal of Infectious Diseases, vol. 191, no. 10, pp. 1599-1611, 2005.

[18] P. E. Van den Steen, I. Van Aelst, S. Starckx, K. Maskos, G. Opdenakker, and A. Pagenstecher, "Matrix metalloproteinases, tissue inhibitors of MMPs and TACE in experimental cerebral malaria," Laboratory Investigation, vol. 86, no. 9, pp. 873-888, 2006.

[19] A. Szklarczyk, M. Stins, E. A. Milward et al., "Glial activation and matrix metalloproteinase release in cerebral malaria," Journal of neurovirology, vol. 13, no. 1, pp. 2-10, 2007.

[20] P. L. Olliaro and D. E. Goldberg, "The Plasmodium digestive vacuole: metabolic headquarters and choice drug target," Parasitology Today, vol. 11, no. 8, pp. 294-297, 1995.

[21] H. Kuhn, A. Hache, and H. Sklenar, "A structural model for the interaction of haem with unsaturated fatty acids explaining its quasi-lipoxygenase activity. Quantum chemical calculations," Biomedica Biochimica Acta, vol. 42, no. 11-12, pp. S175-S176, 1983.

[22] E. Schwarzer, H. Kühn, E. Valente, and P. Arese, "Malariaparasitized erythrocytes and hemozoin nonenzymatically generate large amounts of hydroxy fatty acids that inhibit monocyte functions," Blood, vol. 101, no. 2, pp. 722-728, 2003.

[23] M. Prato, G. Giribaldi, M. Polimeni, V. Gallo, and P. Arese, "Phagocytosis of hemozoin enhances matrix metalloproteinase- 9 activity and TNF- $\alpha$ production in human monocytes: role of matrix metalloproteinases in the pathogenesis of falciparum malaria," Journal of Immunology, vol. 175, no. 10, pp. 6436-6442, 2005.

[24] S. Mitola, M. Strasly, M. Prato, P. Ghia, and F. Bussolino, "IL12 regulates an endothelial cell-lymphocyte network: effect on metalloproteinase-9 production," Journal of Immunology, vol. 171, no. 7, pp. 3725-3733, 2003.

[25] N. H. Phu, N. Day, P. T. Diep, D. J. P. Ferguson, and N. J. White, "Intraleucocytic malaria pigment and prognosis in severe malaria," Transactions of the Royal Society of Tropical Medicine and Hygiene, vol. 89, no. 2, pp. 200-204, 1995.

[26] E. Schwarzer, G. Bellomo, G. Giribaldi, D. Ulliers, and P. Arese, "Phagocytosis of malarial pigment haemozoin by human monocytes: a confocal microscopy study," Parasitology, vol. 123, no. 2, pp. 125-131, 2001.

[27] P. L. Fiori, P. Rappelli, S. N. Mirkarimi, H. Ginsburg, P. Cappuccinelli, and F. Turrini, "Reduced microbicidal and anti-tumour activities of human monocytes after ingestion of Plasmodium falciparum-infected red blood cells," Parasite Immunology, vol. 15, no. 12, pp. 647-655, 1993.

[28] E. Schwarzer, F. Turrini, D. Ulliers, G. Giribaldi, H. Ginsburg, and P. Arese, "Impairment of macrophage functions after ingestion of Plasmodium falciparum-infected erythrocytes or isolated malarial pigment," Journal of Experimental Medicine, vol. 176, no. 4, pp. 1033-1041, 1992.

[29] E. Schwarzer, M. Alessio, D. Ulliers, and P. Arese, "Phagocytosis of the Malarial Pigment, Hemozoin, Impairs Expression of Major Histocompatibility Complex Class II Antigen, CD54, and CD11c in Human Monocytes," Infection and Immunity, vol. 66, no. 4, pp. 1601-1606, 1998.

[30] E. Schwarzer, O. A. Skorokhod, V. Barrera, and P. Arese, "Hemozoin and the human monocyte-a brief review of their interactions," Parassitologia, vol. 50, no. 1-2, pp. 143-145, 2008.

[31] O. A. Skorokhod, M. Alessio, B. Mordmüller, P. Arese, and E. Schwarzer, "Hemozoin (malarial pigment) inhibits differentiation and maturation of human monocyte-derived dendritic cells: a peroxisome proliferator-activated receptor$\gamma$-mediated effect," Journal of Immunology, vol. 173, no. 6, pp. 4066-4074, 2004.

[32] C. Coban, K. J. Ishii, D. J. Sullivan, and N. Kumar, "Purified malaria pigment (hemozoin) enhances dendritic cell maturation and modulates the isotype of antibodies induced by a DNA vaccine," Infection and Immunity, vol. 70, no. 7, pp. 3939-3943, 2002.

[33] C. Coban, K. J. Ishii, T. Kawai et al., “Toll-like receptor 9 mediates innate immune activation by the malaria pigment hemozoin," Journal of Experimental Medicine, vol. 201, no. 1, pp. 19-25, 2005.

[34] G. Giribaldi, D. Ulliers, E. Schwarzer, I. Roberts, W. Piacibello, and P. Arese, "Hemozoin- and 4-hydroxynonenalmediated inhibition of erythropoiesis. Possible role in malarial dyserythropoiesis and anemia," Haematologica, vol. 89, no. 4, pp. 492-493, 2004.

[35] S. Pichyangkul, P. Saengkrai, and H. K. Webster, "Plasmodium falciparum pigment induces monocytes to release high levels of tumor necrosis factor- $\alpha$ and interleukin-1 $\beta$," American Journal of Tropical Medicine and Hygiene, vol. 51, no. 4, pp. 430-435, 1994.

[36] B. A. Sherry, G. Alava, K. J. Tracey, J. Martiney, A. Cerami, and A. F. G. Slater, "Malaria-specific metabolite hemozoin mediates the release of several potent endogenous pyrogens (TNF, MIP- $1 \alpha$, and MIP-1 $\beta$ ) in vitro, and altered thermoregulation in vivo," Journal of Inflammation, vol. 45, no. 2, pp. 85-96, 1995.

[37] M. Prato, V. Gallo, G. Giribaldi, and P. Arese, "Phagocytosis of haemozoin (malarial pigment) enhances metalloproteinase-9 activity in human adherent monocytes: role of IL-1beta and 15-HETE," Malaria Journal, vol. 7, p. 157, 2008.

[38] G. Giribaldi, M. Prato, D. Ulliers et al., "Involvement of inflammatory chemokines in survival of human monocytes fed with malarial pigment," Infection and Immunity, vol. 78, no. 11, pp. 4912-4921, 2010.

[39] M. Prato, V. Gallo, E. Valente, A. Khadjavi, G. Mandili, and G. Giribaldi, "Malarial pigment enhances Heat Shock Protein27 in THP-1 cells: new perspectives for in vitro studies on monocyte apoptosis prevention," Asian Pacific Journal of Tropical Medicine, vol. 3, no. 12, pp. 934-938, 2010.

[40] A. K. Tripathi, D. J. Sullivan, and M. F. Stins, "Plasmodium falciparum-infected erythrocytes increase intercellular adhesion molecule 1 expression on brain endothelium through 
NF- $\kappa \mathrm{B}$," Infection and Immunity, vol. 74, no. 6, pp. 32623270, 2006.

[41] D. Taramelli, N. Basilico, A. M. De Palma et al., "The effect of synthetic malaria pigment ( $\beta$-haematin) on adhesion molecule expression and interleukin- 6 production by human endothelial cells," Transactions of the Royal Society of Tropical Medicine and Hygiene, vol. 92, no. 1, pp. 57-62, 1998.

[42] N. Basilico, L. Speciale, S. Parapini, P. Ferrante, and D. Taramelli, "Endothelin-1 production by a microvascular endothelial cell line treated with Plasmodium falciparum parasitized red blood cells," Clinical Science, vol. 103, supplement 48, pp. 464S-466S, 2002.

[43] N. Basilico, M. Mondani, S. Parapini, L. Speciale, P. Ferrante, and D. Taramelli, "Plasmodium falciparum parasitized red blood cells modulate the production of endothelin-1 by human endothelial cells," Minerva Medica, vol. 95, no. 2, pp. 153-158, 2004.

[44] N. Basilico, S. Parapini, F. Sisto et al., "The lipid moiety of haemozoin (Malaria Pigment) and P. falciparum parasitised red blood cells bind synthetic and native endothelin-1," Journal of biomedicine \& biotechnology, vol. 2010, Article ID 854927, 2010.

[45] P. E. Van den Steen, B. Dubois, I. Nelissen, P. M. Rudd, R. A. Dwek, and G. Opdenakker, "Biochemistry and molecular biology of gelatinase B or matrix metalloproteinase-9 (MMP9)," Critical Reviews in Biochemistry and Molecular Biology, vol. 37, no. 6, pp. 375-536, 2002.

[46] H. C. Brown, T. T. H. Chau, N. T. H. Mai et al., "Blood-brain barrier function in cerebral malaria and CNS infections in Vietnam," Neurology, vol. 55, no. 1, pp. 104-111, 2000.

[47] Y. Ogata, J. J. Enghild, and H. Nagase, "Matrix metalloproteinase 3 (stromelysin) activates the precursor for the human matrix metalloproteinase 9," Journal of Biological Chemistry, vol. 267, no. 6, pp. 3581-3584, 1992.

[48] K. O. Suzuki, J. J. Enghild, T. Morodomi, G. Salvesen, and H. Nagase, "Mechanisms of activation of tissue procollagenase by matrix metalloproteinase 3 (stromelysin)," Biochemistry, vol. 29, no. 44, pp. 10261-10270, 1990.

[49] E. Hahn-Dantona, N. Ramos-DeSimone, J. Sipley, H. Nagase, D. L. French, and J. P. Quigley, "Activation of ProMMP-9 by a plasmin/MMP3 cascade in a tumor cell model. Regulation by tissue inhibitors of metalloproteinases," Annals of the New York Academy of Sciences, vol. 878, pp. 372-387, 1999.

[50] S. Fauser, M. H. Deininger, P. G. Kremsner et al., "Lesion associated expression of urokinase-type plasminogen activator receptor (UPAR, CD87) in human cerebral malaria," Journal of Neuroimmunology, vol. 111, no. 1-2, pp. 234-240, 2000.

[51] M. Toth, I. Chvyrkova, M. M. Bernardo, S. HernandezBarrantes, and R. Fridman, "Pro-MMP-9 activation by the MT1-MMP/MMP-2 axis and MMP-3: role of TIMP-2 and plasma membranes," Biochemical and Biophysical Research Communications, vol. 308, no. 2, pp. 386-395, 2003.

[52] F. Q. Wang, J. So, S. Reierstad, and D. A. Fishman, "Matrilysin (MMP-7) promotes invasion of ovarian cancer cells by activation of progelatinase," International Journal of Cancer, vol. 114, no. 1, pp. 19-31, 2005.

[53] R. Visse and H. Nagase, "Matrix metalloproteinases and tissue inhibitors of metalloproteinases: structure, function, and biochemistry," Circulation Research, vol. 92, no. 8, pp. 827-839, 2003.

[54] G. Murphy, A. Houbrechts, M. I. Cockett, R. A. Williamson, M. O'Shea, and A. J. P. Docherty, "The N-terminal domain of tissue inhibitor of metalloproteinases retains metalloproteinase inhibitory activity," Biochemistry, vol. 30, no. 33, pp. 8097-8102, 1991.

[55] J. P. O’Connell, F. Willenbrock, A. J. P. Docherty, D. Eaton, and G. Murphy, "Analysis of the role of the COOH-terminal domain in the activation, proteolytic activity, and tissue inhibitor of metalloproteinase interactions of gelatinase B," Journal of Biological Chemistry, vol. 269, no. 21, pp. 1496714973, 1994.

[56] J. I. Levin, "The design and synthesis of aryl hydroxamic acid inhibitors of MMPs and TACE," Current Topics in Medicinal Chemistry, vol. 4, no. 12, pp. 1289-1310, 2004.

[57] C. M. Overall and C. López-Otín, "Strategies for MMP inhibition in cancer: innovations for the post-trial era," Nature Reviews Cancer, vol. 2, no. 9, pp. 657-672, 2002.

[58] J. Hu, P. E. Van den Steen, Q. X. A. Sang, and G. Opdenakker, "Matrix metalloproteinase inhibitors as therapy for inflammatory and vascular diseases," Nature Reviews Drug Discovery, vol. 6, no. 6, pp. 480-498, 2007.

[59] M. Wartenberg, S. Wolf, P. Budde et al., "The antimalaria agent artemisinin exerts antiangiogenic effects in mouse embryonic stem cell-derived embryoid bodies," Laboratory Investigation, vol. 83, no. 11, pp. 1647-1655, 2003.

[60] Y. P. Hwang, H. J. Yun, H. G. Kim, E. H. Han, G. W. Lee, and H. G. Jeong, "Suppression of PMA-induced tumor cell invasion by dihydroartemisinin via inhibition of $\mathrm{PKC} \alpha / \mathrm{Raf} /$ MAPKs and NF- $\kappa$ B/AP-1-dependent mechanisms," Biochemical Pharmacology, vol. 79, no. 12, pp. 1714-1726, 2010.

[61] M. Prato, V. Gallo, G. Giribaldi, E. Aldieri, and P. Arese, "Role of the NF- $\kappa$ B transcription pathway in the haemozoin- and 15-HETE-mediated activation of matrix metalloproteinase9 in human adherent monocytes," Cellular Microbiology, vol. 12, no. 12, pp. 1780-1791, 2010.

[62] Y. Wang, Z.-Q. Huang, C.-Q. Wang et al., "Artemisinin inhibits extracellular matrix metalloproteinase inducer (EMMPRIN) and matrix metalloproteinase-9 expression via a protein kinase $\mathrm{C} \delta / \mathrm{p} 38 /$ extracellular signal-regulated kinase pathway in phorbol myristate acetate-induced THP-1 macrophages," Clinical and Experimental Pharmacology and Physiology, vol. 38, no. 1, pp. 11-18, 2011.

[63] A. J. H. Gearing, P. Beckett, M. Christodoulou et al., "Matrix metalloproteinases and processing of pro-TNF- $\alpha$," Journal of Leukocyte Biology, vol. 57, no. 5, pp. 774-777, 1995.

[64] U. Schönbeck, F. Mach, and P. Libby, "Generation of biologically active IL- $1 \beta$ by matrix metalloproteinases: a novel caspase-1-independent pathway of IL- $1 \beta$ processing," Journal of Immunology, vol. 161, no. 7, pp. 3340-3346, 1998.

[65] A. Ito, A. Mukaiyama, Y. Itoh et al., "Degradation of interleukin $1 \beta$ by matrix metalloproteinases," Journal of Biological Chemistry, vol. 271, no. 25, pp. 14657-14660, 1996.

[66] Q. Yu and I. Stamenkovic, "Cell surface-localized matrix metalloproteinase- 9 proteolytically activates TGF- $\beta$ and promotes tumor invasion and angiogenesis," Genes and Development, vol. 14, no. 2, pp. 163-176, 2000.

[67] P. E. Van den Steen, P. Proost, A. Wuyts, JO. Van Damme, and G. Opdenakker, "Neutrophil gelatinase B potentiates interleukin- 8 tenfold by aminoterminal processing, whereas it degrades CTAP-III, PF- 4 , and GRO- $\alpha$ and leaves RANTES and MCP-2 intact," Blood, vol. 96, no. 8, pp. 2673-2681, 2000.

[68] P. E. Van den Steen, A. Wuyts, S. J. Husson, P. Proost, JO. Van Damme, and G. Opdenakker, "Gelatinase B/MMP-9 and neutrophil collagenase/MMP-8 process the chemokines 
human GCP-2/CXCL6, ENA-78/CXCL5 and mouse GCP2/LIX and modulate their physiological activities," European Journal of Biochemistry, vol. 270, no. 18, pp. 3739-3749, 2003.

[69] P. E. Van den Steen, S. J. Husson, P. Proost, J. O. Van Damme, and G. Opdenakker, "Carboxyterminal cleavage of the chemokines MIG and IP-10 by gelatinase B and neutrophil collagenase," Biochemical and Biophysical Research Communications, vol. 310, no. 3, pp. 889-896, 2003.

[70] G. A. McQuibban, G. S. Butler, J. H. Gong et al., "Matrix metalloproteinase activity inactivates the CXC chemokine stromal cell-derived factor-1," Journal of Biological Chemistry, vol. 276, no. 47, pp. 43503-43508, 2001.

[71] E. Fiore, C. Fusco, P. Romero, and I. Stamenkovic, "Matrix metalloproteinase 9 (MMP-9/gelatinase B) proteolytically cleaves ICAM-1 and participates in tumor cell resistance to natural killer cell-mediated cytotoxicity," Oncogene, vol. 21, no. 34, pp. 5213-5223, 2002.

[72] B. C. Sheu, S. M. Hsu, H. N. Ho, H. C. Lien, S. C. Huang, and R. H. Lin, "A novel role of metalloproteinase in cancermediated immunosuppression," Cancer Research, vol. 61, no. 1, pp. 237-242, 2001.

[73] S. J. Giebel, G. Menicucci, P. G. McGuire, and A. Das, "Matrix metalloproteinases in early diabetic retinopathy and their role in alternation of the blood-retinal barrier," Laboratory Investigation, vol. 85, no. 5, pp. 597-607, 2005.

[74] M. Asahi, X. Wang, T. Mori et al., "Effects of matrix metalloproteinase-9 gene knock-out on the proteolysis of blood-brain barrier and white matter components after cerebral ischemia," Journal of Neuroscience, vol. 21, no. 19, pp. 7724-7732, 2001.

[75] É. Beauchesne, P. Desjardins, A. S. Hazell, and R. F. Butterworth, "Altered expression of tight junction proteins and matrix metalloproteinases in thiamine-deficient mouse brain," Neurochemistry International, vol. 55, no. 5, pp. 275$281,2009$.

[76] H. Ichiyasu, J. M. McCormack, K. M. McCarthy, D. Dombkowski, F. I. Preffer, and E. E. Schneeberger, "Matrix metalloproteinase-9-deficient dendritic cells have impaired migration through tracheal epithelial tight junctions," American Journal of Respiratory Cell and Molecular Biology, vol. 30, no. 6, pp. 761-770, 2004.

[77] S. Angelow, P. Zeni, B. Höhn, and H. J. Galla, "Phorbol ester induced short- and long-term permeabilization of the blood-CSF barrier in vitro," Brain Research, vol. 1063, no. 2, pp. 168-179, 2005.

[78] M. Takehara, T. Nishimura, S. Mima, T. Hoshino, and T. Mizushima, "Effect of claudin expression on paracellular permeability, migration and invasion of colonic cancer cells," Biological and Pharmaceutical Bulletin, vol. 32, no. 5, pp. 825831, 2009.

[79] Y. I. Yang, E. Y. Estrada, J. F. Thompson, W. Liu, and G. A. Rosenberg, "Matrix metalloproteinase-mediated disruption of tight junction proteins in cerebral vessels is reversed by synthetic matrix metalloproteinase inhibitor in focal ischemia in rat," Journal of Cerebral Blood Flow and Metabolism, vol. 27, no. 4, pp. 697-709, 2007.

[80] S. Brule, N. Charnaux, A. Sutton et al., "The shedding of syndecan-4 and syndecan-1 from HeLa cells and human primary macrophages is accelerated by SDF-1/CXCL12 and mediated by the matrix metalloproteinase-9," Glycobiology, vol. 16, no. 6, pp. 488-501, 2006.

[81] P. Proost, J. Van Damme, and G. Opdenakker, "Leukocyte gelatinase B cleavage releases encephalitogens from human myelin basic protein," Biochemical and Biophysical Research Communications, vol. 192, no. 3, pp. 1175-1181, 1993.

[82] S. Agrawal, P. Anderson, M. Durbeej et al., "Dystroglycan is selectively cleaved at the parenchymal basement membrane at sites of leukocyte extravasation in experimental autoimmune encephalomyelitis," Journal of Experimental Medicine, vol. 203, no. 4, pp. 1007-1016, 2006.

[83] S. Adams, H. Brown, and G. Turner, "Breaking down the blood-brain barrier: signaling a path to cerebral malaria?" Trends in Parasitology, vol. 18, no. 8, pp. 360-366, 2002.

[84] H. Brown, G. Turner, S. Rogerson et al., "Cytokine expression in the brain in human cerebral malaria," Journal of Infectious Diseases, vol. 180, no. 5, pp. 1742-1746, 1999.

[85] J. B. Dietrich, "The adhesion molecule ICAM-1 and its regulation in relation with the blood-brain barrier," Journal of Neuroimmunology, vol. 128, no. 1-2, pp. 58-68, 2002.

[86] G. Turner, "Cerebral malaria," Brain Pathology, vol. 7, no. 1, pp. 569-582, 1997.

[87] N. Coltel, V. Combes, N. H. Hunt, and G. E. Grau, "Cerebral malaria-a neurovascular pathology with many riddles still to be solved," Current Neurovascular Research, vol. 1, no. 2, pp. 91-110, 2004.

[88] I. M. Medana and G. D. H. Turner, "Human cerebral malaria and the blood-brain barrier," International Journal for Parasitology, vol. 36, no. 5, pp. 555-568, 2006.

[89] H. Brown, T. T. Hien, N. Day et al., "Evidence of bloodbrain barrier dysfunction in human cerebral malaria," Neuropathology and Applied Neurobiology, vol. 25, no. 4, pp. 331340, 1999.

[90] M. R. Gillrie, G. Krishnegowda, K. Lee et al., "Src-family kinase-dependent disruption of endothelial barrier function by Plasmodium falciparum merozoite proteins," Blood, vol. 110, no. 9, pp. 3426-3435, 2007.

[91] N. Geurts, E. Martens, I. Van Aelst, P. Proost, G. Opdenakker, and P. E. Van den Steen, " $\beta$-hematin interaction with the hemopexin domain of gelatinase B/MMP-9 provokes autocatalytic processing of the propeptide, thereby priming activation by MMP-3," Biochemistry, vol. 47, no. 8, pp. 26892699, 2008.

[92] A. C. Schrimpe and D. W. Wright, "Comparative analysis of gene expression changes mediated by individual constituents of hemozoin," Chemical Research in Toxicology, vol. 22, no. 3, pp. 433-445, 2009.

[93] M. Prato, G. Giribaldi, and P. Arese, "Hemozoin triggers tumor necrosis factor alpha-mediated release of lysozyme by human adherent monocytes: new evidences on leukocyte degranulation in P. falciparum malaria," Asian Pacific Journal of Tropical Medicine, vol. 2, no. 3, pp. 35-40, 2009.

[94] M. Prato, E. Valente, D. Ulliers, A. Khadjavi, and G. Giribaldi, "Quercetin, artemisinin and parthenolide abrogate the haemozoin- and 15-HETE-enhanced activity of enzymes released from gelatinase granules by human monocytes," in Proceedings of the Antimal Annual Conference, London, UK, March 2011.

[95] M. Bond, R. P. Fabunmi, A. H. Baker, and A. C. Newby, "Synergistic upregulation of metalloproteinase-9 by growth factors and inflammatory cytokines: an absolute requirement for transcription factor NF- $\kappa \mathrm{B}$," FEBS Letters, vol. 435, no. 1, pp. 29-34, 1998.

[96] K. Sasaki, T. Hattori, T. Fujisawa, K. Takahashi, H. Inoue, and M. Takigawa, "Nitric oxide mediates interleukin-1induced gene expression of matrix metalloproteinases and basic fibroblast growth factor in cultured rabbit articular 
chondrocytes," Journal of Biochemistry, vol. 123, no. 3, pp. 431-439, 1998.

[97] M. Prato, S. D’Alessandro, P. E. Van den Steen et al., "Natural haemozoin modulates matrix metalloproteinases and induces morphological changes in human microvascular endothelium," Cellular Microbiology. In press.

[98] M. Prato, V. Gallo, and P. Arese, "Higher production of tumor necrosis factor alpha in hemozoin-fed-human adherent monocytes is dependent on lipidic component of malarial pigment: new evidences on cytokine regulation in Plasmodium falciparum malaria," Asian Pacific Journal of Tropical Medicine, vol. 3, no. 2, pp. 85-89, 2010.

[99] M. Dell'Agli, G. V. Galli, M. Bulgari et al., "Ellagitannins of the fruit rind of pomegranate (Punica granatum) antagonize in vitro the host inflammatory response mechanisms involved in the onset of malaria," Malaria Journal, vol. 9, no. $1,2010$.

[100] D. Sharma, P. Ottino, N. G. Bazan, and H. E. Bazan, "Epidermal and hepatocyte growth factors, but not keratinocyte growth factor, modulate protein kinase Calpha translocation to the plasma membrane through 15(S)-hydroxyeicosatetraenoic acid synthesis," The Journal of Biological Chemistry, vol. 280, no. 9, pp. 7917-7924, 2005.

[101] S. M. Wyke, J. Khal, and M. J. Tisdale, "Signalling pathways in the induction of proteasome expression by proteolysisinducing factor in murine myotubes," Cellular Signalling, vol. 17, no. 1, pp. 67-75, 2005.

[102] F. L. Chen, X. Z. Wang, J. Y. Li, J. P. Yu, C. Y. Huang, and Z. X. Chen, "12-Lipoxygenase induces apoptosis of human gastric cancer AGS cells via the ERK1/2 signal pathway," Digestive Diseases and Sciences, vol. 53, no. 1, pp. 181-187, 2008.

[103] H. J. Smith, S. H. Wyke, and M. J. Tisdale, "Role of protein kinase $\mathrm{C}$ and NF- $\kappa \mathrm{B}$ in proteolysis-inducing factor-induced proteasome expression in CC myotubes," British Journal of Cancer, vol. 90, no. 9, pp. 1850-1857, 2004.

[104] I. M. Verma and J. Stevenson, "IkappaB kinase: beginning, not the end," Proceedings of the National Academy of Science of United States of America, vol. 94, no. 22, pp. 11758-11760, 1997.

[105] E. Schwarzer, F. Turrini, G. Giribaldi, M. Cappadoro, and P. Arese, "Phagocytosis of P. falciparum malarial pigment hemozoin by human monocytes inactivates monocyte protein kinase C," Biochimica et Biophysica Acta, vol. 1181, no. 1, pp. 51-54, 1993.

[106] J. F. Di Mari, J. I. Saada, R. C. Mifflin, J. D. Valentich, and D. W. Powell, "HETEs enhance IL-1-mediated COX-2 expression via augmentation of message stability in human colonic myofibroblasts," American Journal of Physiology, vol. 293, no. 4, pp. G719-G728, 2007.

[107] Y. Wen, J. Gu, S. K. Chakrabarti et al., "The role of 12/15lipoxygenase in the expression of interleukin- 6 and tumor necrosis factor- $\alpha$ in macrophages," Endocrinology, vol. 148, no. 3, pp. 1313-1322, 2007.

[108] J. Nguyen, J. Gogusev, P. Knapnougel, and B. Bauvois, "Protein tyrosine kinase and p38 MAP kinase pathways are involved in stimulation of matrix metalloproteinase- 9 by TNF- $\alpha$ in human monocytes," Immunology Letters, vol. 106, no. 1, pp. 34-41, 2006.

[109] M. Jaramillo, M. Godbout, and M. Olivier, "Hemozoin induces macrophage chemokine expression through oxidative stress-dependent and -independent mechanisms," Journal of Immunology, vol. 174, no. 1, pp. 475-484, 2005.
[110] L. Flohé, R. Brigelius-Flohé, C. Saliou, M. G. Traber, and L. Packer, "Redox regulation of NF-kappa B activation," Free Radical Biology and Medicine, vol. 22, no. 6, pp. 1115-1126, 1997. 


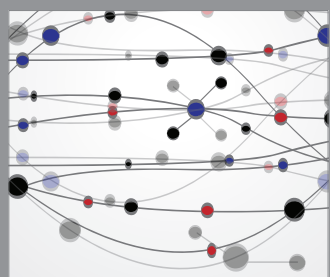

The Scientific World Journal
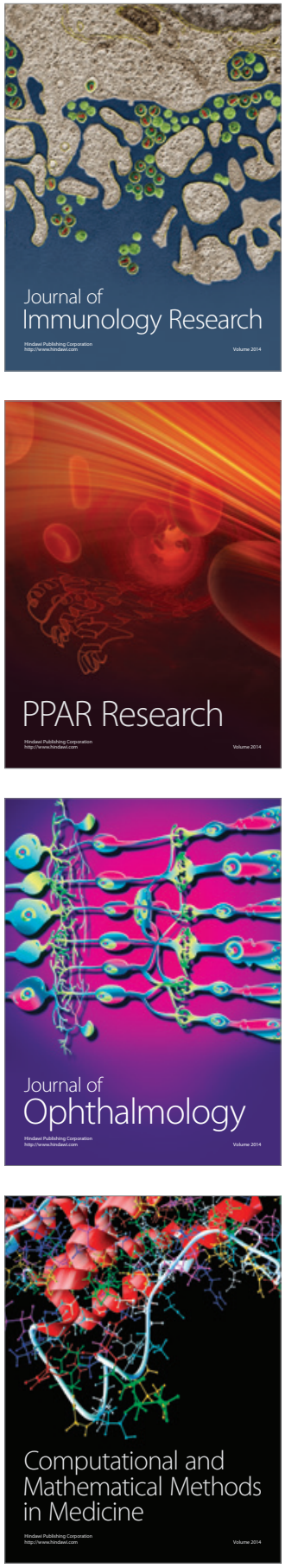

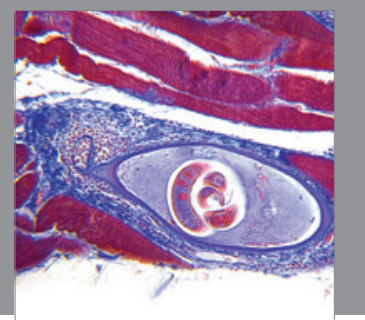

Gastroenterology

Research and Practice
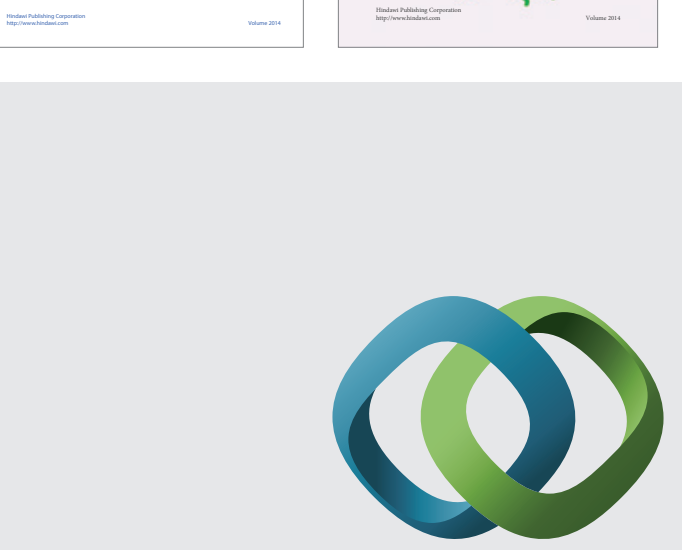

\section{Hindawi}

Submit your manuscripts at

http://www.hindawi.com
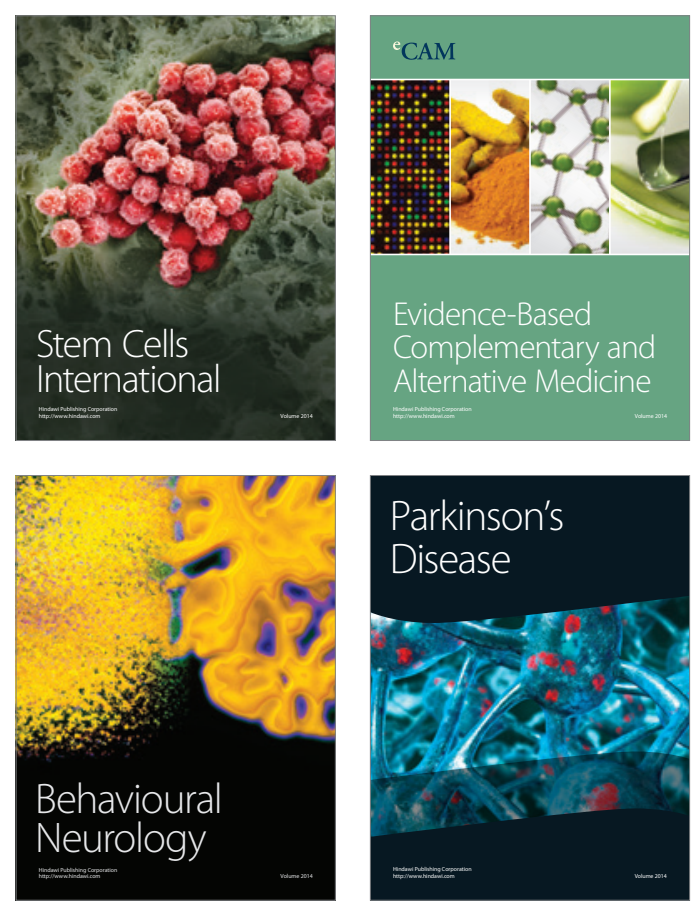

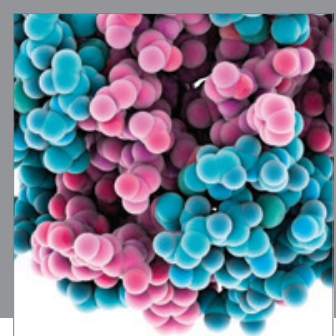

Journal of
Diabetes Research

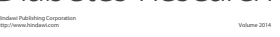

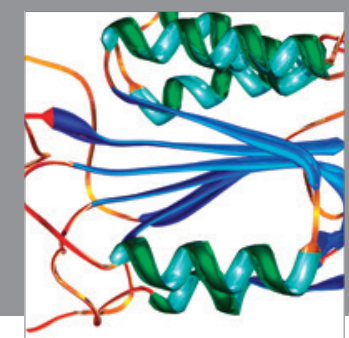

Disease Markers
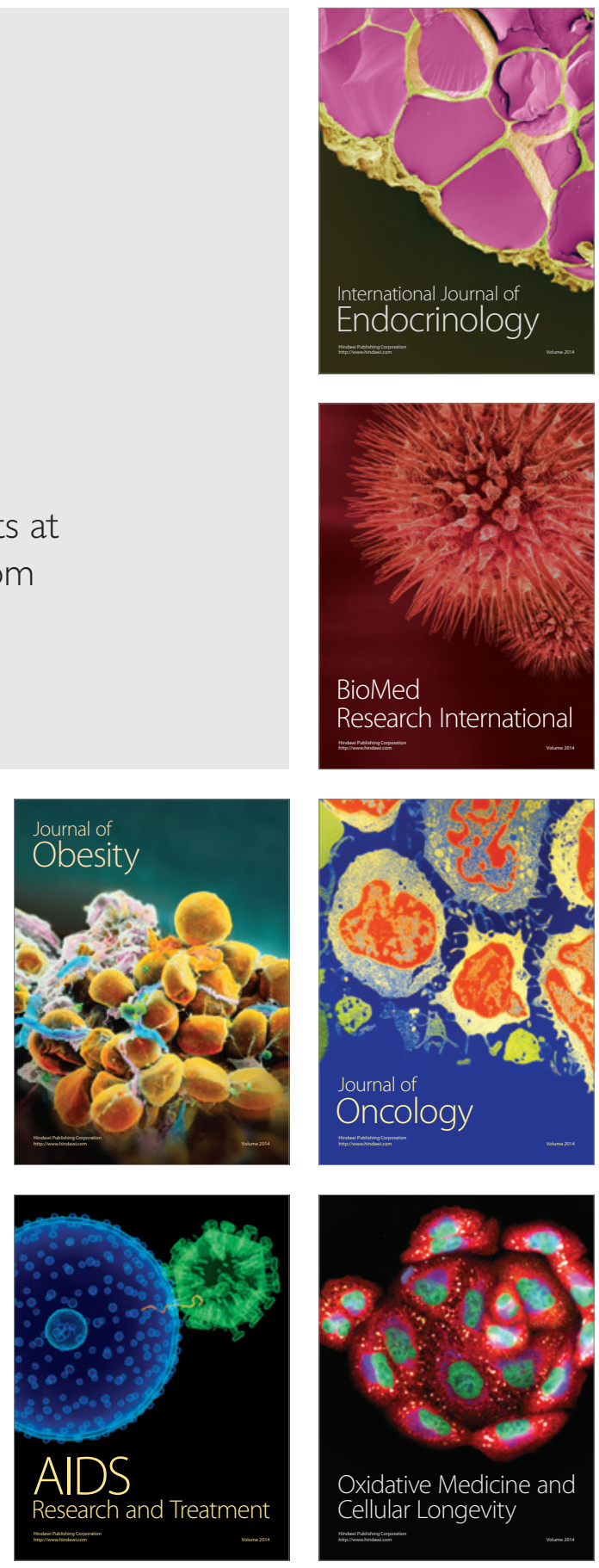